\title{
THE PREPARATION OF MANL'SCRIPTS
}

\section{The attention of authors is particularly directed to the following requests.}

1. Papers should be typed, double-spaced, on one side of white paper (of which A4, 210 by $297 \mathrm{~mm}$. is a suitable size). The pages must be numbered. Margins of $30 \mathrm{~mm}$ should be left at the side. top and bottom of each page. Two clear copies should be sent.

A cover page should give the title, the author's name and institution. with the address at which mail is to be sent.

The title. while brief, must be informative (e.g. A new proof of the prime-number theorem. whereas Some applications of a theorem of $G$. H. Hardy would be useless).

The first paragraph or two should form a summary of the main theme of the paper, providing an abstract intelligible to mathematicians.

For a typescript to be accepted for publication, it must accord with the standard requirements of publishers. and be presented in a form in which the author's intentions regarding symbols ete. are clear to a printer (who is not a mathematician).

The following notes are intended to help the author in preparing the typescript. New authors may well enlist the help of senior colleagues, both as to the substance of their work and the details of setting it out correctly and attractively.

\section{Notation}

Notation should be chosen carefully so that mathematical operations are expressed with all possible neatness, to enlighten the task of the compositor and reduce the chance of error.

For instance $n_{k}(n$ sub $k$ ) is common usage, but avoid if possible using $c$ sub $n$ sub $k$. Fractions are generally best expressed by a solidus. Complicated exponentials like

should be shown in this and no other way.

$$
\exp \left\{z^{2} \sin \theta /\left(1+y^{2}\right)\right\}
$$

In the manuscript, italies, small capitals and capitals are specified by single, double and triple underlinings. Bold-faced type is shown by wavy underlining: wavy will be printed wavy.

It helps if displayed equations or statements which will be qưted later are numbered in order on the right of their line. They can then be referred to by, for example. 'from (7)

The author must enable the printer (if necessary by pencilled notes in the margin) to distinguish between similar symbols such as $0,0,0,0,0 ; x, X, x: \phi, \Phi, \varnothing: 1,1: \epsilon, \epsilon ; \kappa, k$.

Greek letters can be denoted by $G k$ in the margin.

If an author wishes to mark the end of the proof of a theorem. the sign I may be used.

Footnotes should be avoided.

\section{Diagrams}

It is extremely helpful if diagrams are drawn in Indian ink on white eard, faintly blue or green-lined graph paper, or tracing cloth or paper. Symbols. legends and captions should be given on a transparent overlay. Each text figure must be numbered as Figure 1. Figure $2 \ldots$ and its intended position clearly indicated in the manuscript:

\section{Figure 1 here}

The author's name in pencil must be on all separate sheets of diagrams.

A figure is expensive to reproduce and should be included only when the subject matter demands it, or when it greatly clarifies the exposition.

The Society recognizes that some authors do not have the facilities for producing drawings of a sufficiently high standard to be reproduced directly and it is therefore willing to have such diagrams re-drawn. provided that they are clear.

\section{Tables}

Tables should be numbered (above the table) and set out on separate sheets. Indicate the position of each in the text as for figures:

Table 3 here

\section{References}

References should be collected at the end of the paper numbered in alphahetical order of the author's names. Titles of journals should be abbreviated as in Mathematical Rerieus. The following examplea show the preferred style for references to a paper in a journal. a paper in a proceedings volume, a book and an unpublished dissertation:

[1] J. F. ADA Ms. On the non-existence of elements of Hopf invariant one. Ann of Math. (2) 72 (1960). 20-104

[2] M. P. Fotraxs and D. S. Scotr. Sheaves and logic. In Applications of Shearex, Lecture Notes in Math. vol. 753 (Springer-Verlag. 1979). Pp. 302-401.

[3] P. T. Johnstose. Stone Spaces. Cambridge Studies in Advanced Math. no, 3 (C'ambridge Lniversity Press. 1982).

[4] F. W. Lawvere. Functional semantics of algebraic theories. Ph. D. thesis. Columbia University (1963). 


\title{
Mathematical Proceedings of the Cambridge Philosophical Society
}

\author{
MPCPCO 99 (Pt 2) 189-379 (1986) 0305-0041 March 1986
}

\section{CONTENTS}

Onov, R.W. K. A note on trigonometric sums in several variablea $\quad \begin{array}{r}\text { PAGE } \\ 189\end{array}$

Shorey, T. N. Perfect powers in values of certain polynomials at integer points.$\quad 195$

Würfel, Trumann. Extensions of pro-p groups of cohomological dimension two $\quad . \quad 209$

WALL, C. T. C. Real forms of cusp singularities . . . . . . . . . . . . 213

Livingston, Charles. Inequivalent, bordant group actions on a surface . . . . 233

Nicas, ANDREw J. An infinite family of non-Haken hyperbolie 3-manifolds with vanishing Whitehead groups

Morton, H. R. Threading knot diagrams .

Garling, D. J. H. Another 'short' proof of the Riesz representation theorem . . . 261

SARANTOPOULOS, I. Estimates for polynomial norms on $L P(\mu)$ spaces . . . . . $\quad 263$

Lav, Anthony To-Mrna. Continuity of Arens multiplication on the dual space of bounded uniformly continuous functions on locally compact groups and topological semigroups

TAYlor, S. JAmes \& Tricot, Clavde. The packing measure of rectifiable subsets of the plane

Gaudry, Garth I. \& Pini, Rita. Bernstein's theorem for compact, connected Lie groups

Goodman, F. M., Jorgensen, P. E. T. \& Prligrad, C. Smooth derivations commuting with Lie group actions.

COHEN, JosL E. Connectivity of finite anisotropic random graphs and directed graphs

BAXTer, LAURence A. Continuum structures. II

EPLeTt, W. J. R. A fixed point approach to local minimax theory . . . . .

Dткsнгт, H. P. \& ОЈна, A. On convergence and quasiconformality of complex planar spline interpolants.

Galdi, G. P., Knops, R. J. \& Rionero, S. Uniqueness and continuous dependence in the linear elastodynamic exterior and half-space problems.

Galloway, Greoory J. Curvature, causality and completeness in space-times with causally complete spacelike slices

Corrigenda

C) The Cambridge Philosophical Society 1986

CAMBRIDGE UNIVERSITY PRESS

THE PITT BUILDING, TRUMPINGTON STREET, CB 2 IRP

32 EAST 57 TH STREET, NEW YORK, NY IOO22, USA

IO STAMFORD ROAD, OAKLEIGH, MELBOURNE 3166, AUSTRALIA

Price $£ 19.00$ net (USA and Canada US \$44.00)

Subscription price $\$ 50.50$ per volume (£101.00 per annum) net post free

(US \$118.50 per volume (US $\$ 237.00$ per annum) in USA and Canada)

Printed in Great Brilain by the Liniversity Press. Cambridge 